\title{
The six-monthly dental check
}

\section{Derek Richards \\ Editor, Evidence-Based Dentistry}

The six-monthly dental recall has been a mainstay of the dental profession for years but where did the recommendation come from and is it evidence-based?

Evidence-Based Dentistry (2002) 3, 61. doi:10.1038/sj.ebd.6400135

The six-monthly dental recall has been a mainstay of the dental profession for years but where did the recommendation come from and is it evidencebased? Recent correspondence on the dental public health mailing list ${ }^{1}$ suggests that it could go back as far as the Pierre Fauchard in the 18th century: in the English translation of his book ${ }^{2}$ it states, '... Those who are diligent on the conservation of their teeth and who wish to avoid being the victim of their error or their negligence ought to have them examined two or three times every year by an experienced dentist....'

Other claims to the foundation of the 6-monthly check-up discussed on the dental public health mailing list are "The Tooth-ache" imagined by Horace Mayhew and illustrated by George Cruikshank $^{3}$ and a toothpaste advert by Py-Co-Pay Inc. in the 1930s. None of which could be called evidence-based.

The scientific basis for the 6-monthly check was challenged by Sheiham 25 years ago. ${ }^{4}$ Nevertheless, despite a growing acceptance that recall intervals should be based on an individual's risk rather than old dogma, the 6-monthly check has an almost referential place in the dentist's armoury. But how strong is the evidence-base for either argument? Some of the answers to this may be forthcoming because the UK Health Technology Assessment (HTA) programme has commissioned a systematic review of the clinical effectiveness and cost-effectiveness of routine dental checks. The review is currentlyin editorial review (where it seems to have been for a long time) but details can be found at http://www.ncchta.org/ProjectData/ 1_project_record_notpublished.asp? PjtId $=1215$

The National Institute of Clinical Excellence (NICE) here in the UK has announced that it will also look at the dental recall intervals. The remit of NICE is, "to prepare guidance for the [National Health Service] in England and Wales, on the clinical and cost effectiveness of a dental recall examination for all patients at an interval based on the risk from oral disease." Details of the project can be found on the NICE web-site at http://www.nice.org.uk/ article.asp? $\mathrm{a}=33936$.

It is interesting to consider whether the NICE review is wholly necessary if the HTA review has already been conducted and whether NICE will be conducting a further review of the available evidence. At the time of writing, there were only limited details on the NICE web-site. Hopefully more information will be available by the time you read this. One issue this second review does raise, however, is the duplication of effort that may take place. Dentistry and dental research struggles hard enough to gain its share of central research funding so it galling to see money from the same central pool spent twice on the same area, important though that area may be.

Whereas the NICE review will inevitably inform policymakers it is general practitioners who will have to implement any changes. The possible impact on practice of extending the examination interval from 6 to 12 months is considered by Douglas Benn in an editorial later in this issue.

1. Benn D, Leake J, \& Sheiham A. Correspondence on dental-publichealth@list.pitt.edu by Douglas Benn, James Leake and Aubrey Sheiham.

2. Fauchard $P$. The Surgeon Dentist or Treatise on the Teeth (1746). Vol II. Translation. London: Butterworth, 1946:4.

3. The Tooth-ache by Horace Mayhew with illustrations by George Cruikshank. London: D Brogue, 1849.

4. Sheiham A. Is there a scientific basis for sixmonthly dental examinations? Lancet 1977; 2(8035):442-444.

\section{Postscript}

If anyone is aware of a reference regarding the advisability of dental checks earlier than Pierre Fauchard in 1749 the Editor would be interested to know. Contact him at ebdeditor@nature.com. 